\title{
Susceptibilidad de afección por enjambres de medusas (Pelagia noctiluca) en las playas del litoral occidental de la provincia de Málaga
}

\author{
Susceptibility of affection by jellyfish swarms (Pelagia noctiluca) \\ on the beaches of the western coast of the province of Malaga
}

\author{
Ana de la Fuente Roselló ${ }^{1^{*}}$ (ID) \\ Juan Francisco Sortino Barrionuevo ${ }^{2}$ (i) \\ Sergio Jesús Reyes Corredera ${ }^{3}$ (i) \\ María Jesús Perles Roselló ${ }^{4}$
}

\section{Resumen}

En el artículo se analiza y cartografía la susceptibilidad de afección por enjambres de medusas (Pelagia noctiluca) en las playas del litoral occidental de la provincia de Málaga. Los indicadores de peligrosidad de aparición de enjambres se elaboran a partir de un inventario de datos empíricos de avistamientos de medusas, registrados a través de la aplicación InfoMedusa (datos diarios para los meses estivales del periodo 2015-2020). Se proponen distintos indicadores de peligrosidad (frecuencia y severidad), y se calculan parámetros específicos que corrijan el problema del número desigual de observaciones en las playas. Los resultados cartográficos muestran que el patrón de distribución espacial no es aleatorio. Se observa una mayor frecuencia de episodios en las playas más occidentales del tramo estudiado, y el análisis preliminar de los factores condicionantes en cada playa permiten deducir una asociación de las playas con más propensión a recibir enjambres con la amplitud del ángulo de apertura de la misma, así como con la orientación al suroeste del tramo de costa en el que se sitúan las playas. Estas condiciones facilitan la entrada de las corrientes de levante procedentes del mar de Alborán, origen predominante de los enjambres.

Palabras clave: Costa del Sol; Infomedusa; cartografía de susceptibilidad; playas.

\begin{abstract}
The article analyses and maps the hazard of jellyfish swarms (Pelagia Noctiluca) on the western coast of Malaga province. Hazard indicators are based on empirical data from jellyfish sightings recorded with 'InfoMedusa' (daily observations for the summer months of the 2015-2020 period). Various hazard indicators are proposed (frequency and severity) and specific parameters are calculated to correct the problem of unequal numbers of beach observations and its repercussions on the representativeness of the results. The cartographic results show that the spatial distribution pattern is not random. A higher frequency of episodes is observed on the westernmost beaches of the area under study and a preliminary analysis of the conditioning factors in each beach allows us to associate the beaches with the greatest propensity to receive swarms with the width of the opening angle of these beaches - as well as the southwest orientation of the stretch of coast where the beaches are located. These conditions facilitate the entry of eastern currents from the Alboran sea (the main origin of the swarms).
\end{abstract}

Keywords: Costa del Sol; Infomedusa; susceptibility mapping; beaches.

\footnotetext{
1 Departamento de Geografía, Universidad de Málaga, España. anadelafuente@uma.es. * Autora para correspondencia

2 Departamento de Geografía, Universidad de Málaga, España. francis.sortino@uma.es

3 Departamento de Geografía, Universidad de Málaga, España. sergioreyes@uma.es

4 Departamento de Geografía, Universidad de Málaga, España. mjperles@uma.es
} 


\section{Introducción}

Las costas y playas son elementos de indiscutible importancia para el desarrollo económico del territorio en el que se localizan, constituyendo un pilar básico en actividades como el turismo de sol y playa, cuyo atractivo resulta muy sensible a la degradación de estos espacios y a cualquier cambio que genere incertidumbre en su uso (Enríquez y Bujosa, 2020). En las últimas décadas, probablemente motivado por la influencia del ser humano en el funcionamiento del clima y sus consecuencias sobre de los mares y océanos, se han incrementado de una forma alarmante la presencia de floraciones de medusas que acaban por llegar hasta la costa (Dong, 2019; Mills, 2001; Purcell, 2011). En el entorno mediterráneo, estos problemas están especialmente motivados por la medusa clavel (Pelagia noctiluca), que supone la especie potencialmente más dañina de esta área (Bellido el al., 2020). Se trata de una de las especies de medusas más importantes en el Mediterráneo debido a su amplia distribución, abundancia, función ecológica y también especialmente motivado por su interacción negativa con la población (Canepa, Fuentes, Sabatés, Piraino y Boero, 2014), siendo además una de las especies más usuales en los enjambres de medusas en la provincia de Málaga.

El incremento de la frecuencia de aparición de floraciones es analizado por distintos autores. Brotz, Cheung, Keisner, Pakhomov y Pauly (2012) constatan cambios en las poblaciones de medusas y analizan la tendencia al aumento de la presencia de éstas en las costas a partir del año 1950. Asimismo, Purcell, Uye y Lo (2007) pronostica un progresivo incremento de poblaciones de medusas en áreas costeras asociado a la presión antropogénica sobre el mar. Kogovsek, Bogunovic y Malej (2010) analizan las ocurrencias históricas en el mar Adriático en los últimos 200 años combinadas con variables ambientales (temperatura, salinidad, pH, clorofila, peso seco de zooplancton y descargas principales en los ríos), concluyendo que la periodicidad de aparición en forma de plaga se ha acortado en las últimas décadas, aumentando así la recurrencia de las floraciones de esta especie. Los archivos de la Station Zoologique, en el Observatorio Oceanográfico Villefranche-sur-Mer, contienen registros de años con presencia de Pelagia noctiluca y años sin visitas de ésta, indicando que en el periodo de 200 años que va desde 1785 a 1985, se produjeron apariciones masivas de esta especie, con una periodicidad aproximada de doce años. En el caso concreto de la Costa del Sol, el Aula del Mar observa un incremento de frecuencia y magnitud de apariciones de medusas en el litoral malagueño, que parece indicar un cambio de tendencia. En la última década, ha registrado proliferaciones en periodos cíclicos de 2-4 años, cuando con anterioridad los ciclos esperados se estimaban en 10-20 años (Aula del Mar, 2021).

La llegada de enjambres de medusas a las playas de un determinado litoral en cantidad y frecuencia extraordinaria constituye una anomalía con consecuencias negativas sobre la sociedad, que permite clasificarlo, según la Oficina de las Naciones Unidas para la Reducción del Riesgo de Desastres (UNISDR), como un riesgo ambiental de tipo biológico. Estos enjambres acarrean una gran problemática para las costas que lo sufren puesto que, aparte de la pérdida de biodiversidad que conllevan, traen consigo importantes efectos negativos en sectores como la pesca (Sabatés et al., 2010) pero sobre todo en el sector turístico (Ghermandi, Galil, Gowdy y Nunes, 2015; Nunes et al., 2015; Rubio y Gutiérrez, 2020).

El enfoque territorial de análisis del riesgo (Cutter, 1994; Calvo, 2001; Olcina, 2008; Perles y Mérida, 2010; Veyret, Beucher y Bonnard, 2005) destaca la importancia de la posición de los elementos causantes y receptores del daño a la hora de evaluar el riesgo. Perles y Cantarero (2010), de forma más concreta, insisten en la importancia de conocer el patrón espacial con el que se comporta el evento peligroso. Proponen articular el patrón espacial de peligrosidad en áreas causantes de la peligrosidad, líneas o superficies transmisoras de los flujos, y áreas receptoras de los impactos del proceso. Para que un peligro incida sobre un área receptora tiene que existir algún vector de transferencia de materia y energía que los una, y además, el área causante ha de estar situada en una posición topológica que permita esta transferencia. Este enfoque es idóneo para analizar la peligrosidad de llegada de los enjambres de medusas a los distintos puntos del litoral.

Existen investigaciones que se centran en el análisis y predicción del comportamiento espacial y/o temporal de los enjambres, y en la búsqueda de factores condicionantes del proceso. En este sentido, Bellido et al. (2020) indagan en la relación entre los índices atmosféricos y la incidencia de enjambres costeros y encuentran una conexión entre años de incidencia alta de proliferación de enjambres de medusas y lluvias copiosas durante invierno y primavera. (Bellido et al., 2020; Gutiérrez-Estrada et al., 2021). Kogovsek et al. (2010) analizan las ocurrencias históricas en el mar Adriático en los últimos 200 años, combinadas con variables ambientales (temperatura, salinidad, $\mathrm{pH}$, clorofila, peso seco de zooplancton y descargas principales en los ríos), concluyendo que la periodicidad de aparición en forma de plaga se ha acortado en las últimas décadas, aumentando así la recurrencia de las floraciones de esta especie. Asimismo, Goy, Morand y Etienne (1988) manifiestan que, usando un modelo de pronóstico (variables climáticas, temperatura, lluvia y presión atmosférica), se pueden predecir periodos con Pelagia noctiluca. 
Los estudios orientados a conocer y cartografiar el comportamiento espacial de la especie con un sentido más aplicado, puede citarse el Proyecto Medusa, que se crea en 2007, por la Agencia Catalana del Agua en colaboración con el Instituto de Ciencias del Mar de Barcelona (ICM-CSIC), con el objeto de controlar la presencia de medusas y entender su funcionamiento en el espacio y en el tiempo a lo largo de la costa catalana. Este proyecto ha realizado sondeos diarios en época estival en diferentes playas, donde se mapean las mayores concentraciones de medusas varadas. Asimismo, se incorporan en las conclusiones de su estudio la importancia de factores como la producción de medusas en alta mar, así como las estructuras artificiales que propician las condiciones idóneas para su crecimiento y reproducción. También se incluyen los factores que propician su debilitamiento, como son los vientos del sureste (Canepa et al., 2014).

Con respecto a los antecedentes más próximos al área de estudio, cabe señalar el análisis realizado en este ámbito (Rubio y Gutiérrez, 2020) que, para analizar la distribución del fenómeno, utiliza como fuente la recurrencia de búsquedas de información sobre medusas en internet, la publicación de noticias relacionadas de los principales periódicos de Andalucía y encuestas a usuarios de playas en la Costa del Sol. Con este material concluye un patrón de distribución en el que destacan los avistamientos estivales, espacialmente concentrados entre la Costa del Sol Oriental (Málaga) y la Costa Tropical (Granada). La escala de trabajo del citado informe, a diferencia del desarrollado en la presente investigación, no se acerca de forma expresa al litoral, ni desciende al nivel de detalle de la playa, sino se desarrolla a escala regional. Gutiérrez-Estrada et al. (2021) enfocan su estudio al desarrollo de un sistema predictivo de la llegada de medusas a tierra en la Costa del Sol. A una escala más detallada, el trabajo de Olmedo (2019) constituye un referente del comportamiento y peligrosidad de los enjambres de medusas en las playas del sector oriental de la provincia de Málaga.

A nivel de la Costa del Sol (Málaga), un antecedente directo de este trabajo es el informe presentado por el Aula del Mar basado en la aplicación móvil InfoMedusa (https://infomedusa.es). Esta aplicación fue creada por la Diputación Provincial en colaboración con el Aula del Mar para el seguimiento de la aparición masiva de Pelagia noctiluca en las distintas playas que componen este litoral. Suministra datos informativos sobre el comportamiento, evolución, trayectoria e intensidad de la plaga, suponiendo por ello una importante base para la elaboración de modelos predictivos (Bellido, Souviron, Báez, Ferri-Yañez y Salas, 2018). En el ámbito español existen otras plataformas de recopilación de datos tales como MedusApp, Grumering o iMedJelly, con diferentes periodos temporales y escalas espaciales en el fenómeno de avistamiento de medusas, aunque ninguna de ellas tan abundante ni extensa en el área de estudio como InfoMedusa.

A partir de la problemática causada por la llegada de enjambres a la costa, en la realización de esta investigación, se ha considerado de interés analizar cuáles son los patrones espaciales de comportamiento de las medusas a nivel litoral. Se pretende identificar las playas más proclives a recibir medusas como paso previo para la identificación de factores relacionados con esta distribución, y poder proponer, en última instancia, medidas de mitigación idóneas para estas zonas.

De forma específica, se abordan los siguientes objetivos:

1) Explotar la base de datos proporcionada por el programa InfoMedusa, para generar un inventario básico de avistamientos de medusas en las playas del litoral occidental de la provincia de Málaga, para el periodo 2015-2020.

2) Analizar la frecuencia de aparición de medusas en cada playa de la zona de estudio (recurrencia diaria en periodo estival durante seis años), así como su severidad. Ajustar los indicadores de peligrosidad a las particularidades y sesgos de la fuente de datos y del inventario.

3) Elaborar una cartografía de peligrosidad por llegada de enjambres en las playas de la Costa del Sol occidental.

4) Comprobar que la distribución espacial de la peligrosidad de afección muestra un patrón aleatorio o, por el contrario, permite identificar tendencias estructurales en la mayor susceptibilidad de algunas playas.

5) Proponer hipótesis preliminares sobre los factores que pueden estar condicionando la mayor predisposición a recibir medusas manifestada en algunas playas.

\section{Metodología}

Para la elaboración de la cartografía de peligrosidad se han desarrollado las siguientes fases de trabajo:

1) Delimitación espacial y cartografía de las playas del litoral occidental de la provincia de Málaga. Identificación de sus principales características fisiográficas y otros factores que puedan relacionarse como posibles factores condicionantes de la mayor o menor presencia de medusas.

2) Volcado y tratamiento inicial de depuración de la base de datos proporcionada por el programa InfoMedusa. Tránsito de la información cualitativa (comentarios) hacia cuantitativa (dato numérico) y asignación del número de registros a cada playa. 
3) Selección para el estudio de las playas con un número de registros válidos que garanticen la fiabilidad de los datos.

4) Análisis de la frecuencia y severidad de aparición de medusas en cada playa de la zona de estudio (recurrencia diaria durante los meses estivales durante un periodo de seis años).

5) Elaboración de la cartografía de susceptibilidad mediante el software de procesamiento geoespacial ArcGis.

6) Análisis de posibles factores explicativos del patrón espacial de peligrosidad observado.

\subsection{Selección del área de estudio}

El análisis de la frecuencia y severidad de la aparición de medusas se ha aplicado al conjunto de playas del litoral occidental malagueño. Tras una primera fase de revisión y depuración de los datos en todas las playas, se han seleccionado, para una segunda fase de estudio, las 12 playas que reúnen una totalidad de registros suficiente como para ser consideradas fiables, además de una casuística variada en lo que se refiere a factores que puedan resultar explicativos de una mayor o menor propensión a recibir enjambres. (playas de Guadalhorce, Guadalmar, Los Álamos, La Carihuela, Las Gaviotas, Los Boliches, Dunas de Artola, El Cable, La Rada, El Cristo, Playa Ancha y Sabinillas, recogidas en la Figura 1).

Se han seleccionado playas de extensión diversa, que se distribuyen a lo largo de unos $90 \mathrm{~km}$ del litoral (Tabla 1). Se ha procurado que en la muestra exista una casuística variada en función de los criterios recogidos en la guía de playas del Ministerio para la Transición Ecológica y el Reto Demográfico (MITECO). Se ha atendido principalmente a características como el carácter, clasificando las playas en urbana, cuando esta se encuentra integrada en el entramado urbano, semiaislada, si tiene acceso a alguna urbanización de baja densidad edificativa y aislada, cuando no existen urbanizaciones en el frente costero. También se han tenido en cuenta las condiciones de baño (oleaje moderado y aguas tranquilas), el tipo y composición de la arena el cual, aunque muy similar en la totalidad del tramo de costa analizado, puede distinguir entre arena y grava, y si se localizan en zonas protegidas. Además, en la selección, se ha procurado que las playas abarquen la práctica totalidad de los términos municipales que componen el tramo de costa. En la Figura 2 se muestran imágenes en las que se observa las mencionadas características. De forma añadida, la alta dependencia de este sector del territorio respecto a la actividad turística justifica sobradamente el interés del análisis en la zona.

Se ha determinado que la unidad de análisis y representación de la peligrosidad en esta investigación sea la playa, frente a otras opciones utilizadas en otras investigaciones similares, como por ejemplo el municipio. La playa es la delimitación fisiográfica mínima en las que las características morfológicas y los procesos funcionales costeros se comportan de forma sistémica, y constituyen una unidad. Por este motivo, la playa constituye la unidad especial idónea a la hora de interpretar la mayor susceptibilidad a recibir medusas de algunos sectores del litoral, y las causas que pueden explicar esta mayor afección.

Figura 1. Playas seleccionadas como área de estudio

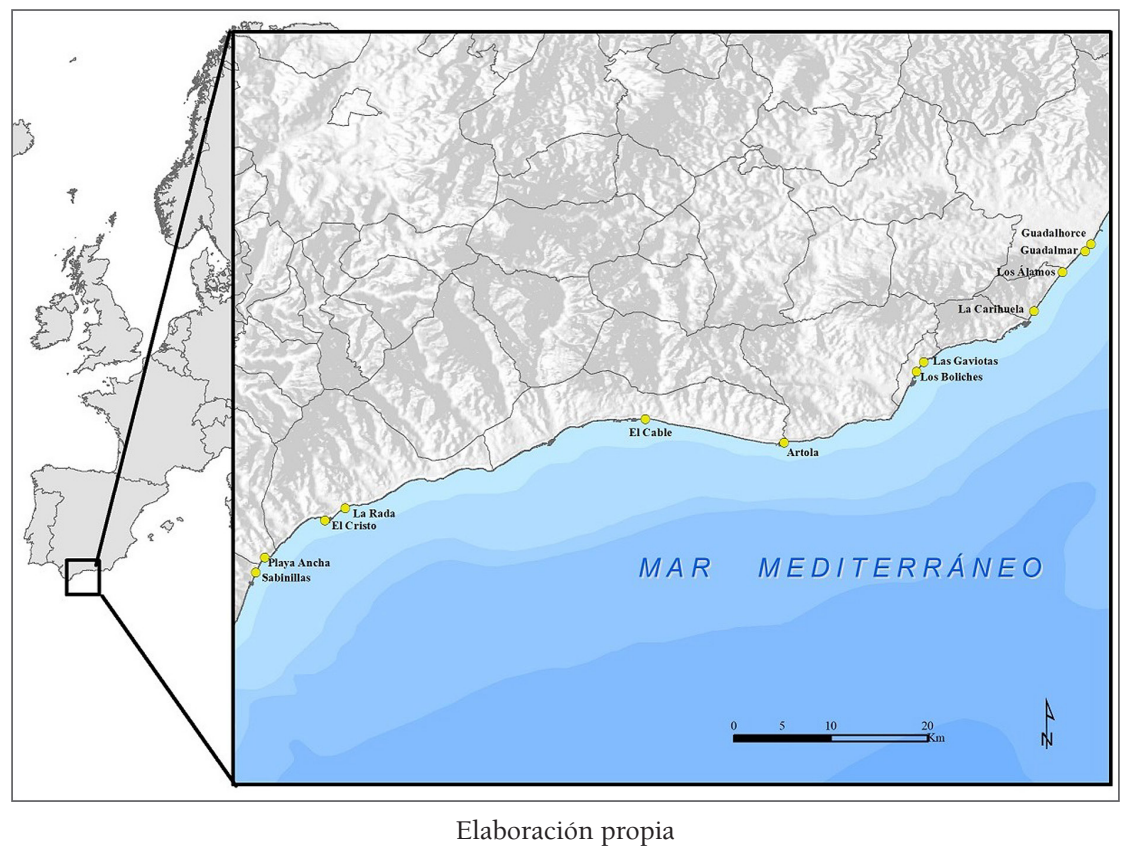


Tabla 1. Características de las playas objeto de estudio

\begin{tabular}{|c|c|c|c|c|c|c|c|c|c|c|c|}
\hline Playa & $\begin{array}{l}\text { Término } \\
\text { municipal }\end{array}$ & $\begin{array}{l}\text { Longitud } \\
\text { (metros) }\end{array}$ & $\begin{array}{l}\text { Anchura } \\
\text { (metros) }\end{array}$ & $\begin{array}{l}\text { Grado de } \\
\text { urbanización }\end{array}$ & $\begin{array}{l}\text { Paseo } \\
\text { marítimo }\end{array}$ & $\begin{array}{l}\text { Condiciones } \\
\text { de baño }\end{array}$ & $\begin{array}{l}\text { Fachada } \\
\text { litoral }\end{array}$ & $\begin{array}{l}\text { Tipo de } \\
\text { arena }\end{array}$ & Composición & $\begin{array}{c}\text { Zona } \\
\text { protegida }\end{array}$ & Descripción \\
\hline Guadalhorce & Málaga & 950 & 60 & Aislada & No & $\begin{array}{l}\text { Oleaje } \\
\text { moderado }\end{array}$ & $\begin{array}{l}\text { Dunas / } \\
\text { Humedal }\end{array}$ & Oscura & Arena & $\begin{array}{l}\text { RENPA } \\
\text { Paraje } \\
\text { natural }\end{array}$ & $\begin{array}{l}\text { Playa junto a la desembocadura del río Guadalhorce, con escasa } \\
\text { afluencia de público. }\end{array}$ \\
\hline Guadalmar & Málaga & 400 & 30 & Semiurbana & No & $\begin{array}{l}\text { Oleaje } \\
\text { moderado }\end{array}$ & $\begin{array}{l}\text { Urbana / } \\
\text { Dunas }\end{array}$ & Oscura & Arena & No & $\begin{array}{l}\text { Forma parte de la zona conocida como playa de San Julian, cerca } \\
\text { de la desembocadura del río Guadalhorce. Presenta un alto grado } \\
\text { de urbanización }\end{array}$ \\
\hline La Carihuela & Torremolinos & 2100 & 30 & Urbana & Sí & $\begin{array}{l}\text { Oleaje } \\
\text { moderado }\end{array}$ & Urbana & Oscura & Arena & No & $\begin{array}{l}\text { Playa con un alto nivel de servicios, ambiente familiar y muy fre- } \\
\text { cuentada. }\end{array}$ \\
\hline Los Álamos & Torremolinos & 1500 & 60 & Semiurbana & No & $\begin{array}{l}\text { Oleaje } \\
\text { moderado }\end{array}$ & Semiurbana & Dorada & Arena & No & Playa familiar. La más alejada del centro de Torremolinos. \\
\hline Las Gaviotas & Fuengirola & 1200 & 40 & Urbana & Sí & $\begin{array}{l}\text { Aguas } \\
\text { tranquilas }\end{array}$ & Urbana & Oscura & Arena & No & Buen nivel de servicios y alta ocupación. \\
\hline Los Boliches & Fuengirola & 1100 & 40 & Urbana & Sí & $\begin{array}{l}\text { Aguas } \\
\text { tranquilas }\end{array}$ & Urbana & Oscura & Arena & No & $\begin{array}{l}\text { Playa muy popular, bien equipada, en el centro urbano de Fuen- } \\
\text { girola. }\end{array}$ \\
\hline $\begin{array}{l}\text { Dunas de } \\
\text { Artola }\end{array}$ & Marbella & 1200 & 30 & Aislada & No & $\begin{array}{l}\text { Oleaje } \\
\text { moderado }\end{array}$ & Semiurbana & Dorada & Arena & $\begin{array}{l}\text { RENPA } \\
\text { Parque } \\
\text { Natural }\end{array}$ & Playa situada en una zona protegida denominada Dunas de Artola. \\
\hline El Cable & Marbella & 400 & 40 & Semiurbana & No & $\begin{array}{l}\text { Oleaje } \\
\text { moderado }\end{array}$ & $\begin{array}{l}\text { Dunas / } \\
\text { Semiurbana }\end{array}$ & Oscura & Arena & No & $\begin{array}{l}\text { Playa formada por una franja de arena estrecha, con poca afluencia } \\
\text { de público. }\end{array}$ \\
\hline El Cristo & Estepona & 700 & 25 a 10 & Semiurbana & No & $\begin{array}{l}\text { Aguas } \\
\text { tranquilas }\end{array}$ & $\begin{array}{l}\text { Semiurbana } \\
\text { / Humedal }\end{array}$ & Oscura & Arena & $\begin{array}{l}\text { Zona } \\
\text { protegida } \\
\text { de interés } \\
\text { ornitológico }\end{array}$ & $\begin{array}{l}\text { Playa del casco urbano, aunque algo retirada del centro, junto al } \\
\text { Puerto Deportivo de Estepona. Forma una bonita cala, regenerada } \\
\text { recientemente, configurando una zona abrigada y resguardada de } \\
\text { los vientos. }\end{array}$ \\
\hline La Rada & Estepona & 2300 & 80 a 50 & Urbana & Sí & $\begin{array}{l}\text { Aguas } \\
\text { tranquilas }\end{array}$ & Urbana & Oscura & Arena & No & $\begin{array}{l}\text { Playa situada frente al casco urbano, ha sido recientemente rege- } \\
\text { nerada. Muy extensa y concurrida, cuenta con gran número de } \\
\text { servicios. }\end{array}$ \\
\hline Playa Ancha & Casares & 1300 & 50 & Urbana & Sí & $\begin{array}{c}\text { Aguas } \\
\text { tranquilas }\end{array}$ & Urbana & Oscura & Grava & $\begin{array}{l}\text { Zona } \\
\text { protegida } \\
\text { de interés } \\
\text { ornitológico }\end{array}$ & $\begin{array}{l}\text { Aguas tranquilas y gran afluencia de público. Dotada con un buen } \\
\text { número de servicios. }\end{array}$ \\
\hline Sabinillas & Manilva & 1700 & 50 & Urbana & Sí & $\begin{array}{l}\text { Aguas } \\
\text { tranquilas }\end{array}$ & Urbana & Oscura & Arena & No & $\begin{array}{l}\text { Se extiende entre el Puerto Deportivo y el río Manilva. El frente } \\
\text { litoral está ocupado por el núcleo de San Luis de Sabinillas. }\end{array}$ \\
\hline
\end{tabular}

Fuente: MITECO, 2021. Elaboración propia 
Figura 2. Imágenes de playas seleccionadas

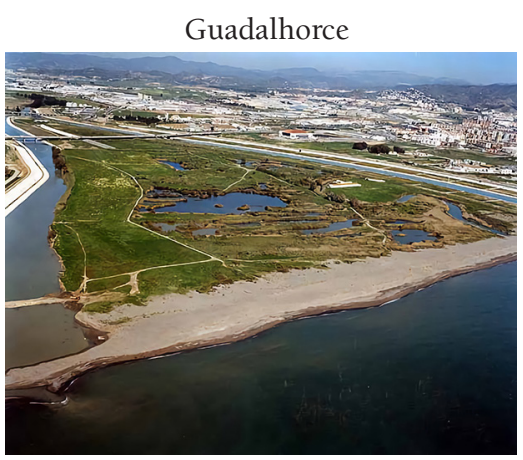

Fuente: Diario Sur (s.f.)

Los álamos

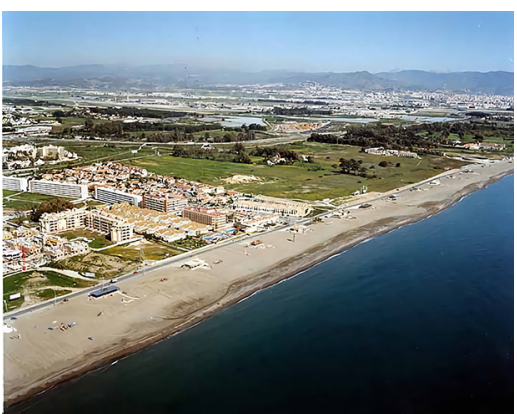

Fuente: Diario Sur (s.f.)

La Carihuela

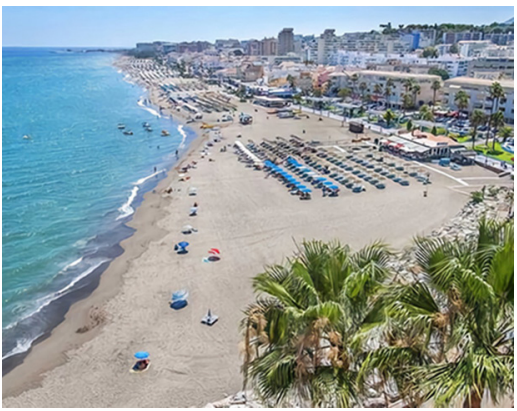

Fuente: Aforo Costa del Sol (s.f.)

El Cristo

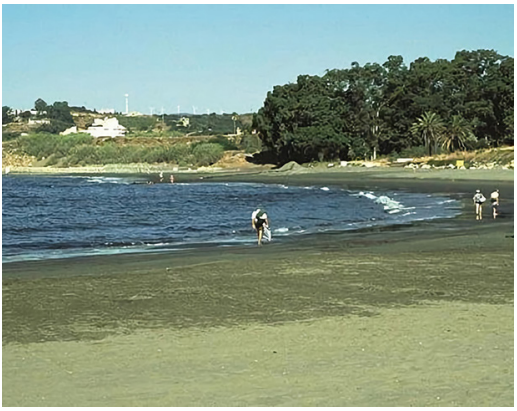

Fuente: Turismo y Planificación Costa del Sol SLU (s.f.)
Guadalmar

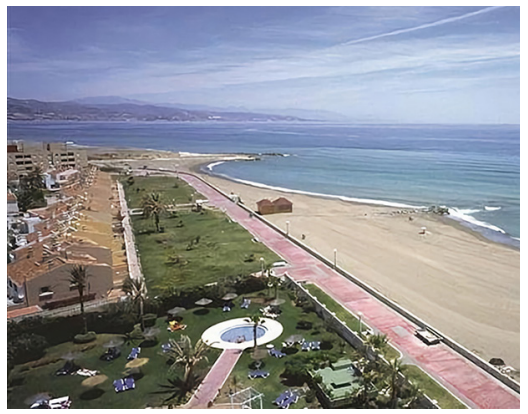

Fuente: Turismo y Planificación Costa del Sol SLU (s.f.)

Las Gaviotas

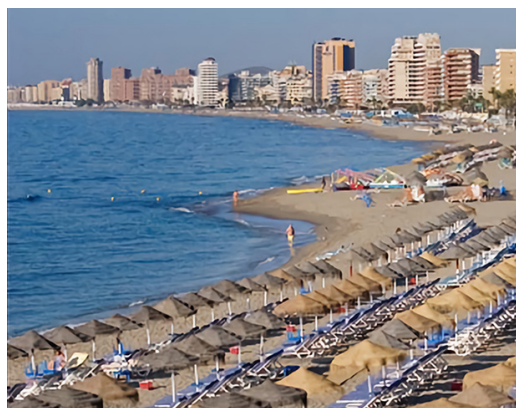

Fuente: Diputación de Málaga (s.f.)

El Cable

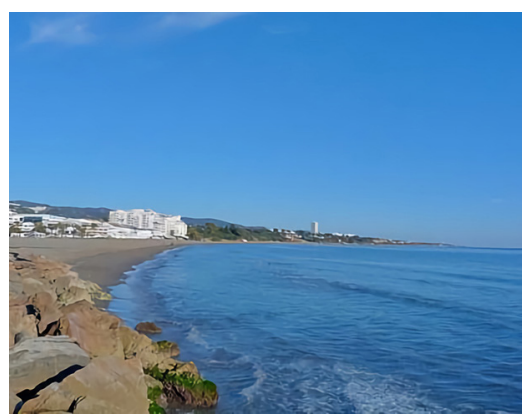

Fuente: Costalsur (s.f.)

Playa Ancha

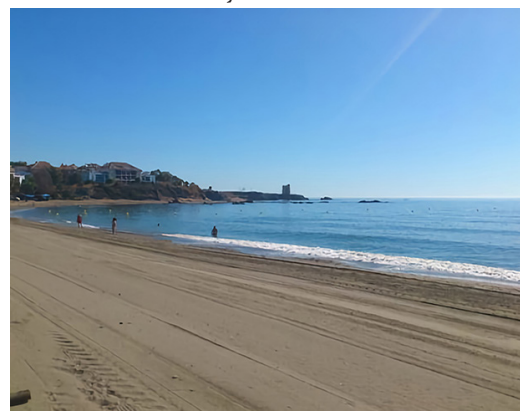

Fuente: Ayuntamiento de Casares (s.f.)
Dunas de Artola

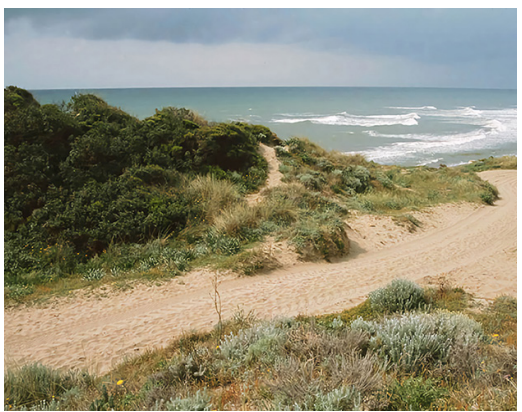

Fuente: Consejería de Agricultura, Ganadería, Pesca y Desarrollo Sostenible (s.f.)

Los Boliches

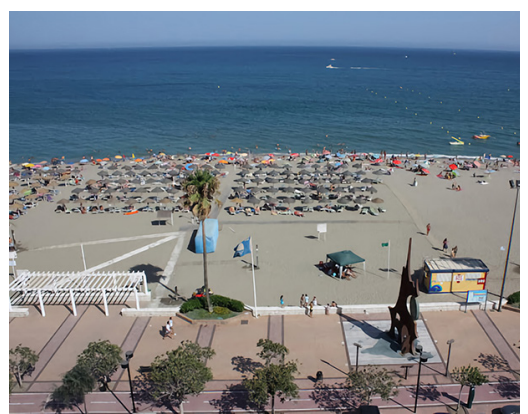

Fuente: Narrogeographic (16/09/2011)

La Rada

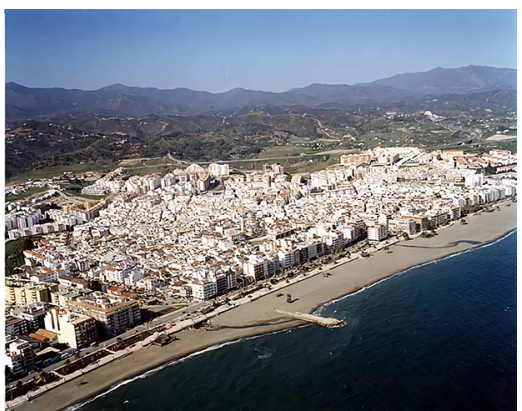

Fuente: Diario Sur (s.f.)

Sabinillas

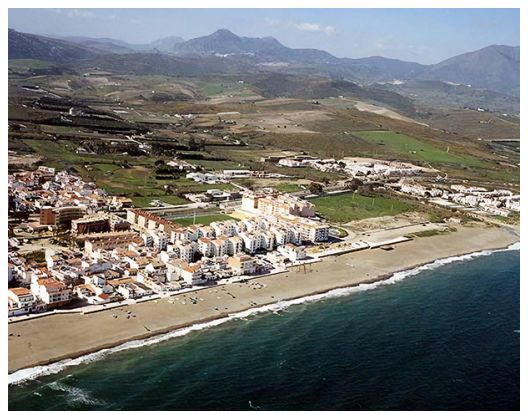

Fuente: Inspain (s.f.)

\subsection{Características de la base de datos InfoMedusa y tratamiento y depuración de los datos}

La investigación se fundamenta en los datos ofrecidos por la aplicación informática InfoMedusa (https://infomedusa.es), activada en 2013 por parte de la Diputación Provincial en colaboración con 
el Aula del Mar. La aplicación tiene como objetivo informar sobre la actividad de las medusas en las playas del litoral malagueño y es realizada gracias a la colaboración ciudadana, que participa mediante la introducción de comentarios acerca de la presencia o no de medusas clasificadas por playas. La base de datos asociada constituye una importante fuente a tratar y explotar, pero requiere una labor previa de transformación de los registros, expresados en forma de comentarios generales sobre el estado de la mar, en datos fehacientes y concretos sobre ausencia o presencia de enjambres.

Para la utilización de la base de datos en cuestión, ha sido necesario tomar una serie de decisiones iniciales, y aplicar una serie de procesos de depuración:

1) Interpretación y filtrado de comentarios, con la eliminación de errores y clasificación de los comentarios relevantes o útiles para el estudio. Hay que señalar que los comentarios son expresados de forma libre por los usuarios, por lo que existe un variado patrón de observaciones.

2) Delimitación del periodo de información en el que los datos poseen la suficiente calidad como para poder ser utilizados para un propósito científico, que se concreta en la serie temporal que transcurre desde el año 2015 al 2020 durante los meses de junio a septiembre.

3) Selección de las playas a analizar en el tramo de estudio seleccionado en razón de la totalidad de registros de datos de cada playa. Se han eliminado del análisis las playas del tramo occidental de la Costa del Sol con menos de 500 registros. Este valor de exclusión se ha obtenido tomando como referencia el total de anotaciones del año 2018, el cual supone, con diferencia, el que posee un mayor número total de comentarios. A partir del registro total de datos del año de referencia sobre el total de playas de la costa occidental de Málaga presentes en la aplicación (170), se ha obtenido el valor medio de 576, 4, que se ha redondeado a la baja para facilitar el análisis.

Total comentarios año 2018: 98.004.

Total playas: 170 .

Promedio: $576,49$.

4) Diseño de matriz de volcado de datos diarios depurados por playas, que contiene la serie temporal comentada, las playas objeto de análisis y las variables seleccionadas.

Para sistematizar los datos obtenidos de los comentarios de los usuarios de la aplicación, la información se ha clasificado en cuatro categorías (Tabla 2).

Tabla 2. Clasificación de los comentarios de InfoMedusa

\begin{tabular}{|c|c|}
\hline Clasificación de medusas & Comentario \\
\hline 0 & Comentario irrelevante \\
\hline 1 & No presencia de medusas \\
\hline 2 & Presencia de medusas dispersas \\
\hline 3 & Presencia de enjambres \\
\hline
\end{tabular}

Elaboración propia

Se han consultado de forma directa y manual un total de 16.726 comentarios para las playas objeto de este estudio. Tras los procesos de filtrado y depuración de la base de datos han resultado un total de 1.885 registros útiles para el estudio.

\subsection{Análisis de la frecuencia y severidad de aparición de medusas. Indicadores calculados}

Para obtener datos diarios de la presencia o ausencia de medusas en cada playa en un formato binario (sí/no), los dos grados de severidad diferenciados en el inventario (Presencia de medusas dispersas/ presencia de enjambres) han sido unificados en uno sólo, ya que ambos indican la presencia de medusas. Se han calculado distintos parámetros indicadores de la frecuencia de medusas en la playa: por una parte, se ha procedido a ponderar el número de registro por la superficie útil de la playa, entendiendo que la superficie de la playa puede resultar un indicador aproximado de la afluencia o potencial de visitas de cada una de ellas. El indicador obtenido se ha denominado Número de días con medusas ponderado por la superficie de la playa. Asimismo, para evitar el problema de la diferente afluencia en función de la localización, se ha aplicado un coeficiente de minoración para las playas alejadas de los circuitos de acceso urbano, multiplicando por 0,5 la superficie de la playa.

Paralelamente, para el análisis comparativo de las anotaciones diarias de presencia/ausencia de medusas entre playas, se han calculado datos porcentuales relativos al total de registros en cada playa (número 
de días con y sin medusas para cada playa en relación al total de registros de la misma). Se han obtenido dos indicadores: Porcentaje de días con medusas respecto al total de registros de la playa y Porcentaje de días sin medusas respecto al total de registros de la playa. A continuación, para clasificar en intervalos los distintos indicadores de peligrosidad calculados y asignar los correspondientes grados de gravedad, se han utilizados dos criterios: intervalos de naturaleza estadística (media y desviación estándar) en el caso de las variables Número de días con y sin medusas ponderado por la superficie de la playa, e intervalos regulares para el indicador Porcentaje de días con y sin medusas. En este último caso, se ha optado por estandarizar los intervalos para el conjunto de las playas a partir del valor máximo presente en la muestra, esto es, el porcentaje de días con medusas máximo en las playas del área de estudio, a fin de observar con mayor claridad las diferencias entre playas y afinar la comparación entre ellas. Las Tablas 3, 4 y 5 recogen los intervalos asignados.

Tabla 3. Media y desviación estándar de las variables número de días con y sin medusas ponderado por la superficie de la playa

\begin{tabular}{|c|c|c|}
\hline Cálculos & Número de días con medusas & Número de días sin medusas \\
\hline$\Sigma$ superficie de la playa & 248,54 & 366,91 \\
\hline $\bar{x}$ & 20,71 & 30,58 \\
\hline$\sigma$ & 24,38 & 38,47 \\
\hline $1 / 2 \sigma$ & 12,19 & 19,24 \\
\hline
\end{tabular}

En razón de los estadísticos obtenidos, se han definido tres intervalos de gravedad del peligro (Tabla 4).

Tabla 4. Días con medusas ponderado por la superficie de la playa. Intervalos de peligrosidad

\begin{tabular}{|c|c|c|}
\hline $\begin{array}{c}\text { Intervalos en función } \\
\text { de la superficie de la playa }\end{array}$ & Días con medusas & Días sin medusas \\
\hline 1 & $<9$ & $<12$ \\
\hline 2 & $10-31$ & $12-50$ \\
\hline 3 & $>31$ & $>50$ \\
\hline \multicolumn{2}{|c|}{ Elaboración propia }
\end{tabular}

Tabla 5. Porcentaje de días con y sin medusas. Intervalos asignados

\begin{tabular}{|c|c|c|}
\hline $\begin{array}{c}\text { Intervalos en función } \\
\text { de datos relativos }\end{array}$ & Días con medusas & Días sin medusas \\
\hline 1 & $<38$ & $<52$ \\
\hline 2 & $38-47$ & $52-61$ \\
\hline 3 & $>47$ & $>61$ \\
\hline
\end{tabular}

Elaboración propia

La representación gráfica y cartográfica de estos indicadores y sus intervalos se ha realizado siguiendo la semiótica de color del semáforo. La representación cartográfica se ha ejecutado mediante el programa de procesamiento geoespacial ArcGis.

\subsection{Asignación de intervalos de peligrosidad a los distintos indicadores}

Como se ha citado anteriormente, el número de registros (comentarios en InfoMedusa, 2020) no es homogéneo entre las distintas playas. Para discriminar las playas que son más y menos fiables para este estudio en razón del número de anotaciones de usuarios disponible, se han calculado los valores medios de comentarios para el conjunto del área de estudio y su desviación estándar (Tabla 7). A partir de estos datos, se han considerado, por una parte, fiables aquellas playas que tienen un número de registros en 
torno a la media menos $1 / 2$ desviación estándar y/o superiores a ella. Por otra parte, se consideran playas poco fiables las que disponen de un número inferior a la media menos $1 \frac{1}{2}$ desviación estándar (Tabla 6).

Tabla 6. Número de registros por playa. Media y desviación estándar

\begin{tabular}{|c|c|}
\hline Cálculos & Registros de datos \\
\hline$\Sigma$ & 594,90 \\
\hline $\bar{x}$ & 49,58 \\
\hline$\sigma$ & 57,37 \\
\hline $1 / 2 \sigma$ & 28,68 \\
\hline \multicolumn{2}{|c}{} \\
\hline
\end{tabular}

Tabla 7. Intervalos de fiabilidad de la playa en función del número de registros

\begin{tabular}{|c|c|}
\hline $\begin{array}{c}\text { Intervalos de fiabilidad } \\
\text { de las playas }\end{array}$ & Días con medusas \\
\hline Poco fiable & $<21$ \\
\hline Fiable & $21-78$ \\
\hline Muy fiable & $>78$ \\
\hline
\end{tabular}

Elaboración propia

En una fase posterior, para evaluar la fiabilidad de los datos ofrecidos por la playa, se ha utilizado una estrategia añadida. Se ha procedido a constatar que, si una playa presenta un elevado número de días con medusas, no coincida con la observación contraria, esto es, que tenga a la vez un número elevado de días sin medusas, lógica que invalidaría la consistencia de la afirmación primera. Se ha considerado que, si la playa ofrece un número elevado de días con medusas y a la vez un número elevado de días sin medusas, la contradicción hace perder fiabilidad a ambas observaciones. A partir de este análisis, la fiabilidad de los datos ofrecidos por cada playa se rige por el razonamiento que se muestra en la Tabla 8.

Tabla 8. Criterios aplicados para deducir la fiabilidad de los datos en cada playa

\begin{tabular}{|l|l|}
\hline Playa fiable & $\begin{array}{l}\text { Se considera que una playa es fiable cuándo tiene un más de 21 de registros } \\
\text { (dato ponderado por la superficie de la playa) y una diferencia entre los días con } \\
\text { y sin medusas mayor al } 60 \% .\end{array}$ \\
\hline Playa fiable proclive a las medusas & Playa con un porcentaje de registro de días con medusas mayor al $60 \%$. \\
\hline Playa fiable no proclive a las medusas & Playa con un porcentaje de registro de días sin medusas mayor al $60 \%$. \\
\hline Playa no fiable & $\begin{array}{l}\text { Se considera que una playa no es fiable cuándo tiene un número de registros por } \\
\text { debajo de la media y/o una escasa diferencia entre los días con medusas y los } \\
\text { días sin medusas (del } 50 \text { al } 60 \% \text { ) }\end{array}$ \\
\hline
\end{tabular}

Elaboración propia

\section{Resultados}

Tras el proceso de consulta directa y manual de un total de 16.726 comentarios referentes a las playas seleccionadas, los comentarios han sido depurados y filtrados en razón de su calidad y representatividad estadística, ofreciendo como resultado un total de 1.885 registros útiles para el estudio, datos que centran el análisis en un total de 12 playas del litoral occidental. Como puede observarse en la Figura 3, los resultados muestran que existe una notable disparidad en el número de comentarios útiles ( $\mathrm{n}^{\circ}$ de registros) entre las distintas playas, que oscila entre 57 en Guadalhorce y 264 en La Carihuela.

Los valores de frecuencia expresados en valores absolutos son más elevados en las playas con más registros, tanto para el indicador de días con medusas como para su contrario, días sin medusas (Figuras 4 y 5). Este hecho resta valor comparativo a los indicadores de peligrosidad expresados en valores absolutos, tales como el Número absoluto de días con medusas representado en la Figura 6, en la que, como puede observarse, las playas Los Álamos, La Carihuela, Los Boliches y La Rada presentan los valores más elevados de frecuencia de afección por medusas. 
Figura 3. Número de días con registros de medusas

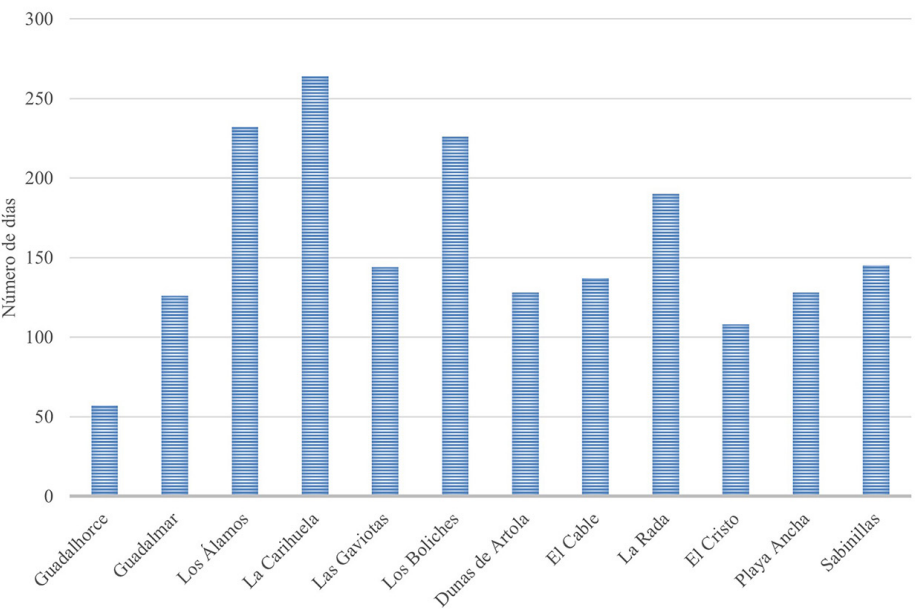

Fuente: InfoMedusa, 2020. Elaboración propia

Figura 4. Días con medusas por playas. Medias del periodo de análisis y datos absolutos

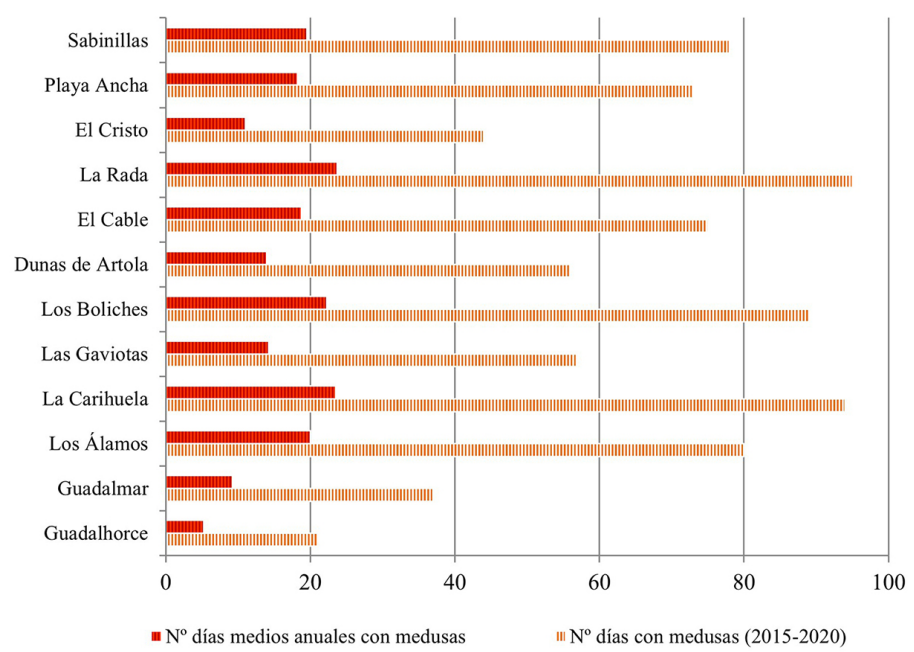

Fuente: InfoMedusa, 2020. Elaboración propia

Figura 5. Días sin medusas por playas. Medias del periodo de análisis y datos absolutos

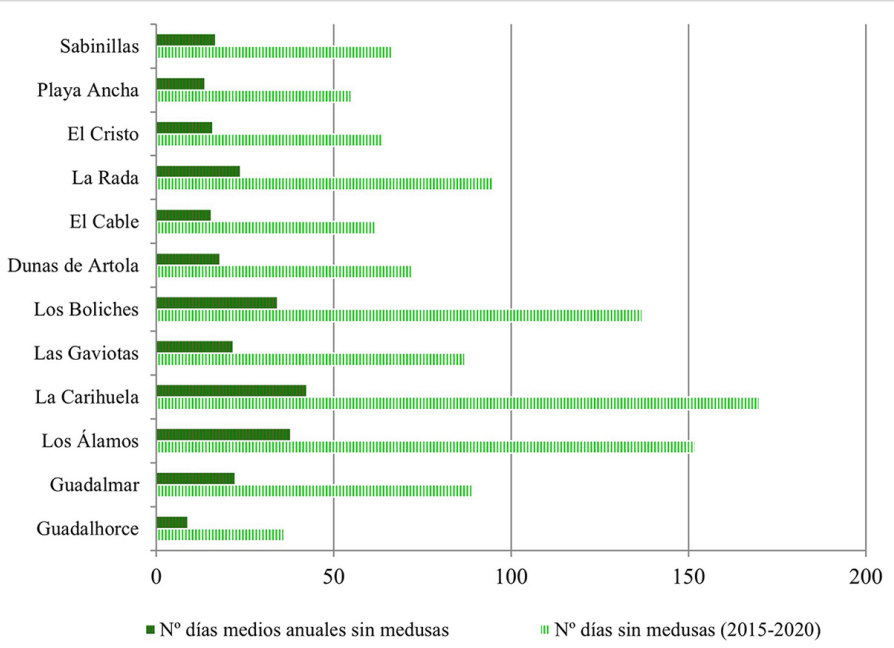

Fuente: InfoMedusa, 2020. Elaboración propia 
Figura 6. Días con medusas por playas. Datos absolutos

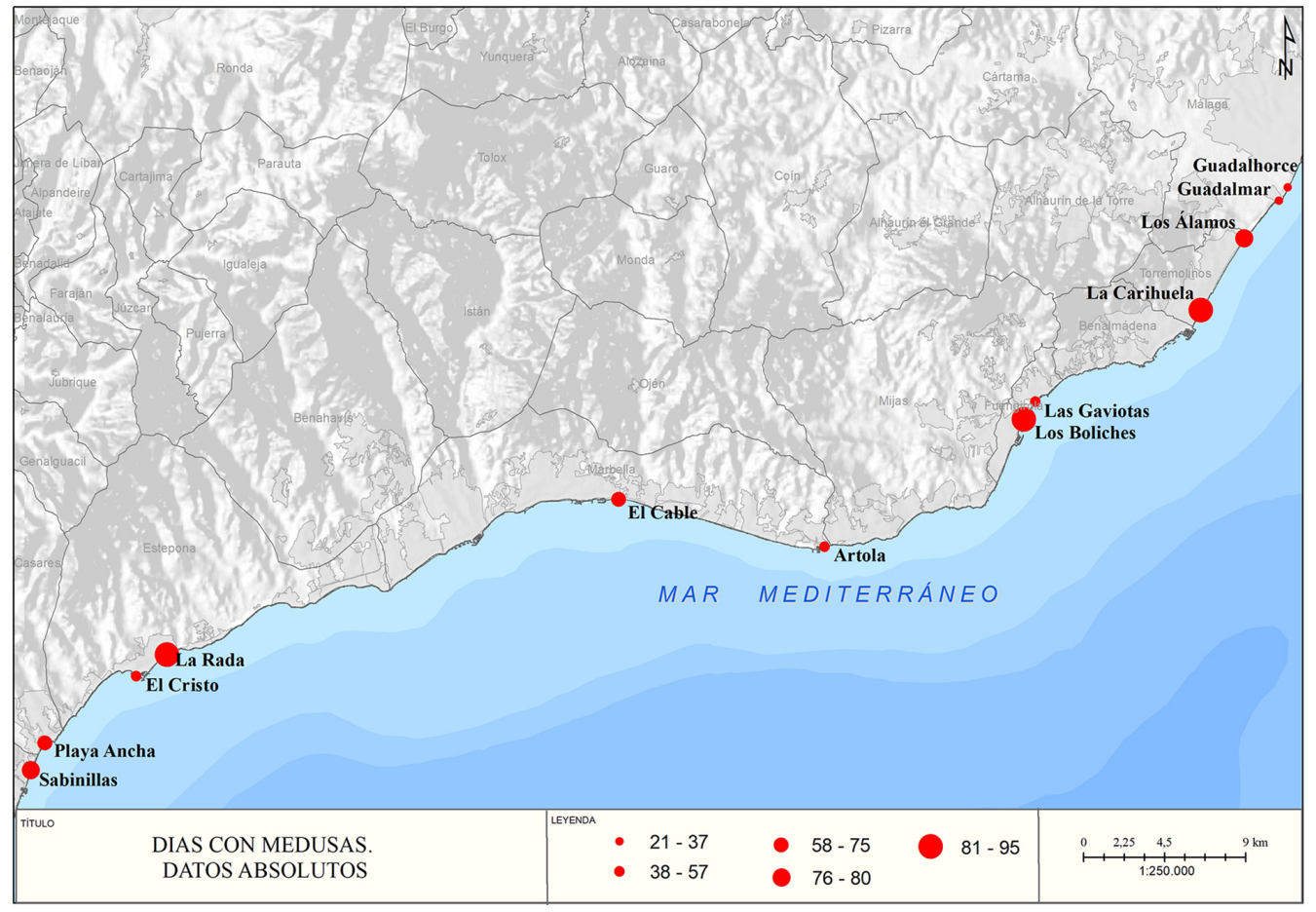

Fuente: InfoMedusa, 2020. Elaboración propia

Al objeto de matizar el problema que introduce en la interpretación el hecho de que las playas tengan un número de registro tan dispar, se ha calculado el indicador de frecuencia ponderado por la superficie de la playa. En la Tabla 9 se muestra el resultado de la ponderación de los días con medusas con respecto a la superficie total de la playa, así como los cálculos realizados para la obtención del valor medio y los intervalos de gravedad establecidos con relación al mismo. Los valores superiores a la media aparecen resaltados en la Tabla 9.

Tabla 9. Número de días con medusas ponderado por la superficie de la playa

\begin{tabular}{|c|c|}
\hline Playa & Días con medusas \\
\hline Guadalhorce & 3,81 \\
\hline Guadalmar & 23,49 \\
\hline Los Álamos & 7,50 \\
\hline La Carihuela & 4,52 \\
\hline Las Gaviotas & 9,90 \\
\hline Los Boliches & 81,00 \\
\hline Dunas de Artola & 42,38 \\
\hline El Cable & 9,31 \\
\hline La Rada & 7,29 \\
\hline El Cristo & 28,79 \\
\hline Playa Ancha & 13,05 \\
\hline Sabinillas & 9,51 \\
\hline$\Sigma$ & 248,54 \\
\hline $\bar{x}$ & 20,71 \\
\hline$\sigma$ & 24,38 \\
\hline $1 / 2 \sigma$ & 12,19 \\
\hline
\end{tabular}

Elaboración propia 
Como resultado de la aplicación de la ponderación por superficie se ha obtenido el resultado mostrado en la Figura 7.

Figura 7. Número de días con medusas ponderado por la superficie total de la playa

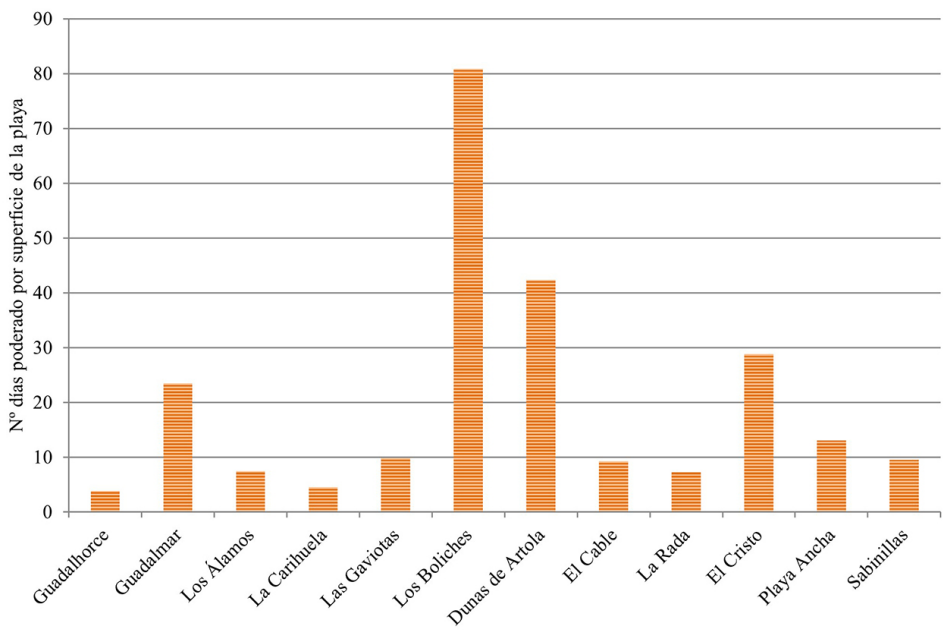

Fuente: InfoMedusa, 2020. Elaboración propia

Considerando la superficie de cada playa, los datos varían notablemente, destacando sobre todo la playa de Los Boliches y, en menor medida, Dunas de Artola, como las que más porcentaje de medusas han registrado en función de su superficie, siendo éstas las únicas playas que se sitúan en el intervalo 3, por encima de la media considerada. El mapa resultante clasificado en intervalos se muestra en la Figura 8.

Figura 8 Intervalos de días con medusas ponderado por la superficie total de la playa

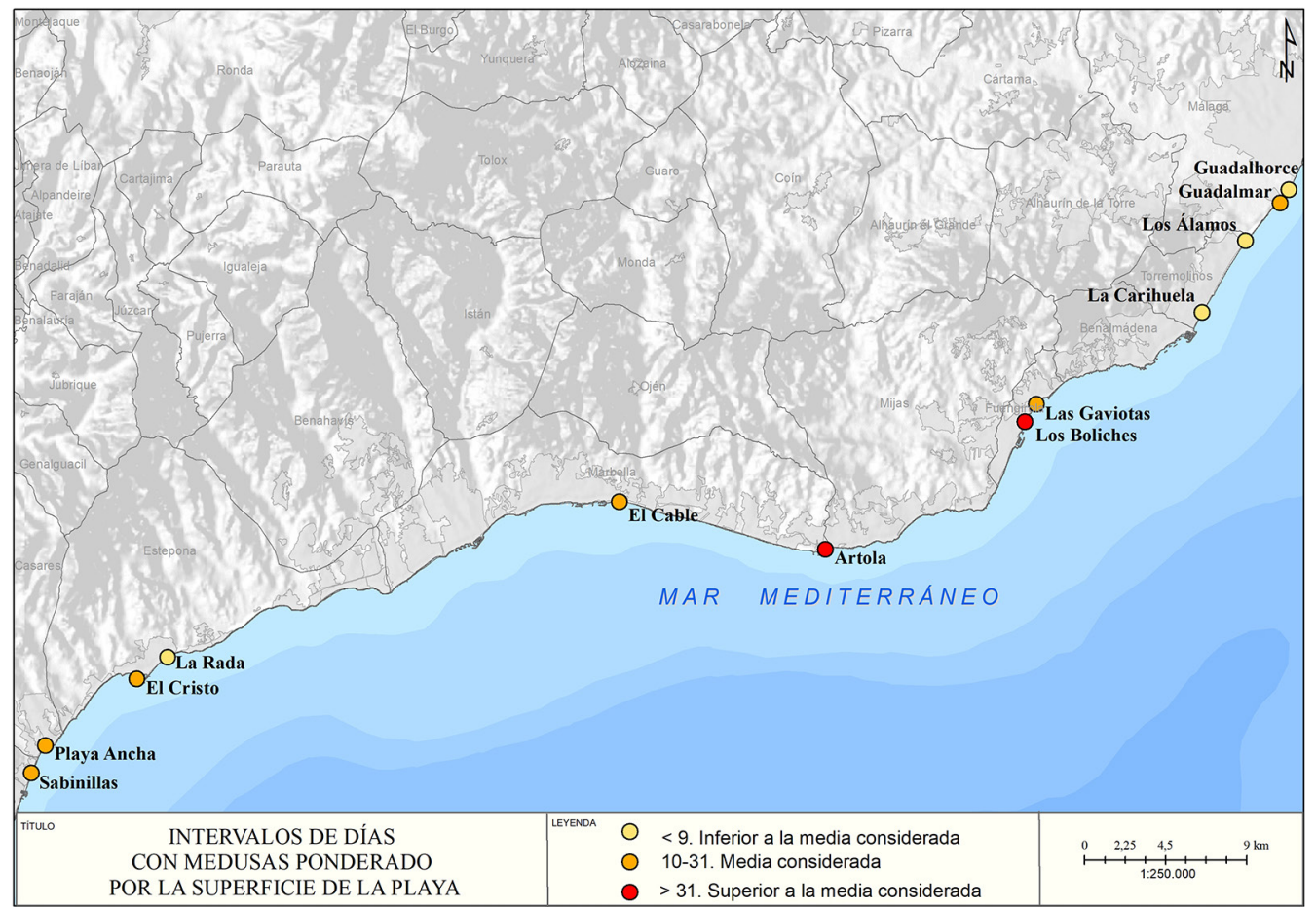

Fuente: InfoMedusa, 2020. Elaboración propia

Sin un patrón de continuidad, se pueden distinguir tres niveles de presencia de medusas: inferior a la media considerada (playas de Guadalhorce, Los Alamos, La Carihuela y La Rada), playas en la media considerada (Las Gaviotas, El Cable, El Cristo, Playa Ancha y Sabinillas) y playas con valores superiores a la media considerada (Los Boliches y Dunas de Artola). 
Una vez comprobado que con el cálculo de intervalos regulares no se aprecia de manera conveniente las diferencias entre playas, para una mejor apreciación de las diferencias entre playas y en un intento de homogeneizar los datos de presencia de medusas, se ha optado por la realización de intervalos relativos al máximo y mínimo porcentaje de la muestra. El resultado del análisis previo comparativo entre datos registrados de presencia y ausencia de medusas en base 100 se puede ver en la Figura 9.

Figura 9. Porcentaje de presencia/ausencia de medusas por playas. Datos relativos

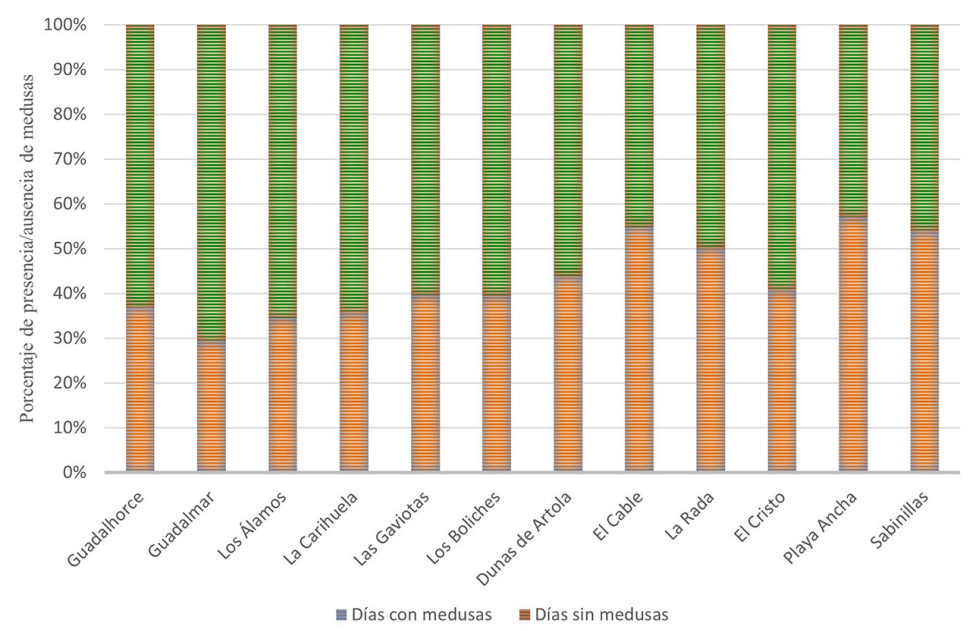

Fuente: InfoMedusa, 2020. Elaboración propia

Los resultados de los cálculos relativos de los días con medusas se presentan en la Tabla 10, en la cual se resaltan los valores superiores a la media.

Tabla 10. Porcentaje de días con medusas con intervalos relativos a la muestra de la zona de estudio

\begin{tabular}{|c|c|}
\hline Playa & Presencia de medusas \\
\hline Guadalhorce & 36,84 \\
\hline Guadalmar & 29,37 \\
\hline Los Álamos & 34,48 \\
\hline La Carihuela & 35,61 \\
\hline Las Gaviotas & 39,58 \\
\hline Los Boliches & 39,38 \\
\hline Dunas de Artola & 43,75 \\
\hline El Cable & 54,74 \\
\hline La Rada & 50,00 \\
\hline El Cristo & 40,74 \\
\hline Playa Ancha & 57,03 \\
\hline Sabinillas & 53,79 \\
\hline$\Sigma$ & 515,32 \\
\hline $\bar{x}$ & 42,94 \\
\hline$\sigma$ & 8,95 \\
\hline $1 / 2 \sigma$ & 4,48 \\
\hline
\end{tabular}

Elaboración propia

En el análisis del porcentaje de días con medusas con intervalos relativos a la muestra de la zona de estudio se han definido tres intervalos. En la Figura 10 se representan los resultados ordenados de menor a mayor y por tonalidades de color. En este análisis se observan, a grandes rasgos, menos diferencias entre playas que en la ponderación por superficies. De entre los intervalos definidos, como playas con menos presencia de medusas, se encuentran Guadalmar, Los Álamos y La Carihuela. A continuación, en el intervalo intermedio se presentan cinco playas, estas son, Guadalhorce, Los Boliches, Las Gaviotas, 
El Cristo y Dunas de Artola. En el último intervalo, con más días de medusas por playas, están La Rada, Sabinillas, El Cable y Playa Ancha.

Figura 10. Porcentaje de días con medusas por playa con intervalos relativos a la muestra de la zona de estudio

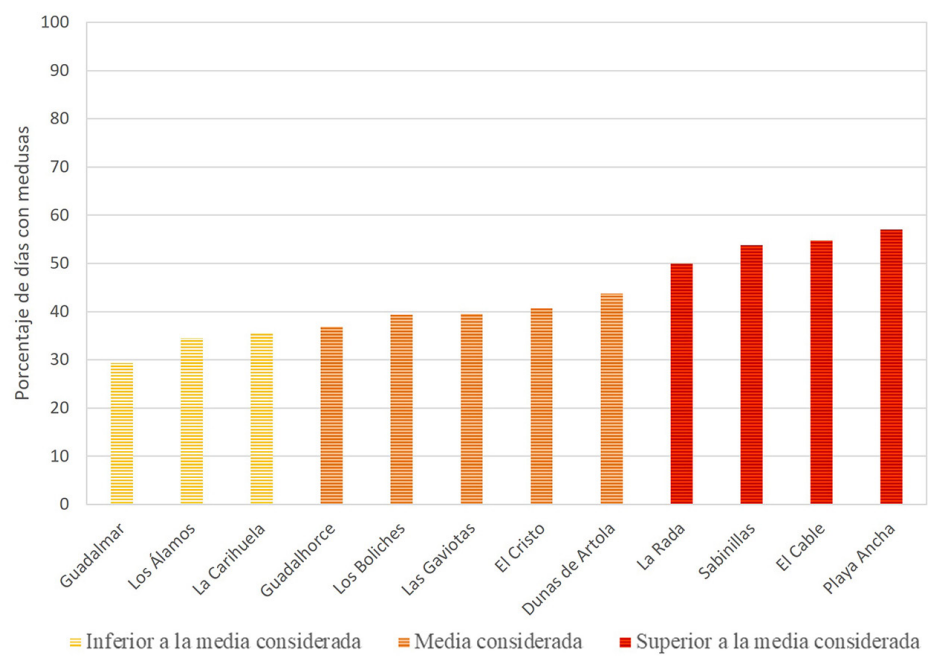

Fuente: InfoMedusa, 2020. Elaboración propia

El análisis con datos porcentuales relativos permite observar, con mayor claridad, un patrón de distribución espacial de la peligrosidad bastante definido, con una disposición este-oeste en la que aumenta progresivamente la presencia de medusas (Figura 11).

Figura 11. Intervalos con datos relativos de presencia de días con medusas por playas

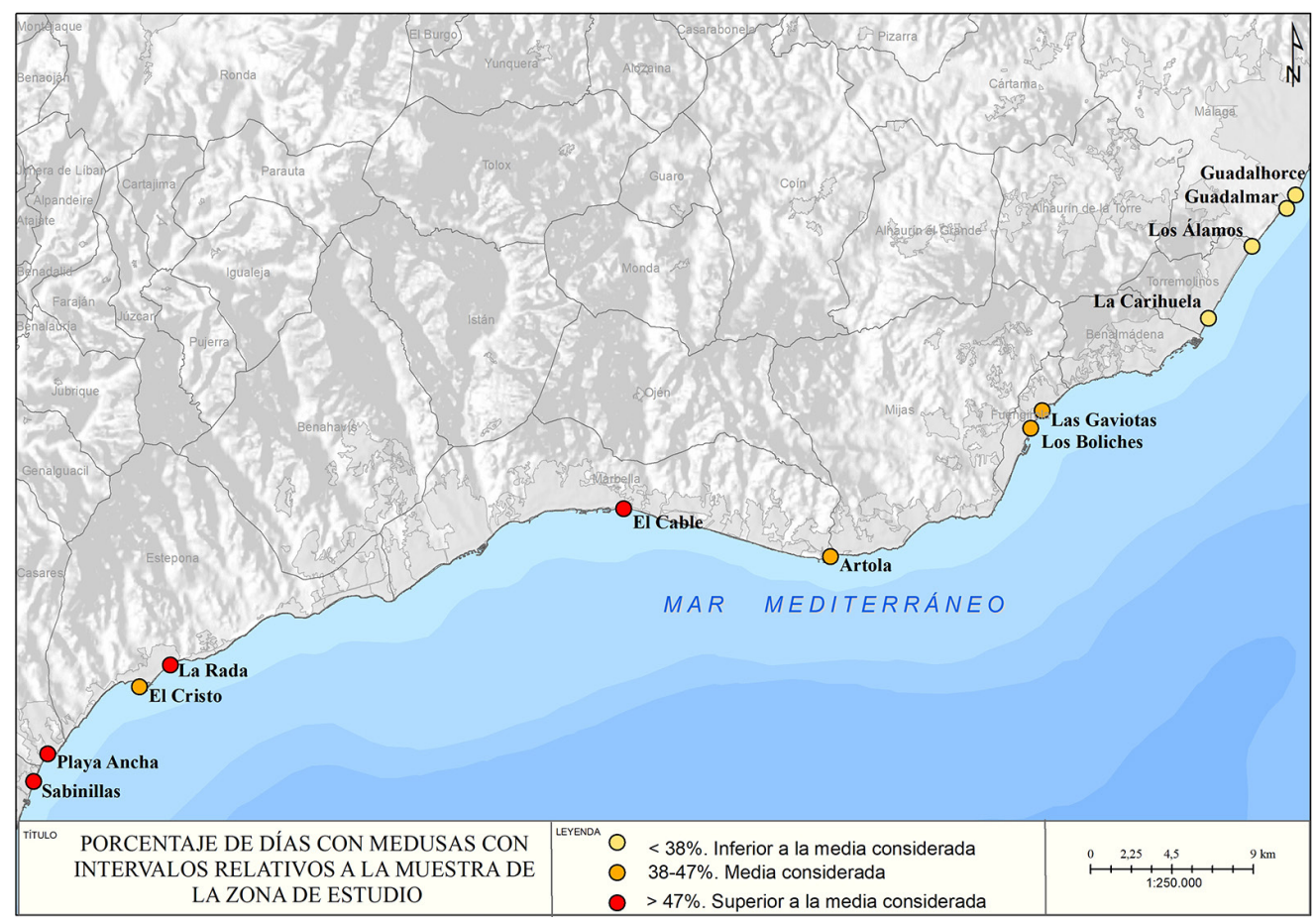

Fuente: InfoMedusa, 2020. Elaboración propia

\section{Discusión}

La bibliografía sobre los ciclos de aparición de floraciones de medusas en el mediterráneo y su llegada a la costa está poniendo de manifiesto un acortamiento progresivo de los ciclos. La mayoría de los autores, a la hora de buscar causas explicativas al incremento de la frecuencia en zonas costeras, han trabajado 
a escala regional. Entre las causas aludidas para esta tendencia, se citan la presión antropogénica sobre las zonas litorales y su impacto directo en los mares y océanos (Condon et al., 2013; Duarte et al., 2013; Purcell, 2011). Otros autores apuntan como los efectos del cambio climático inciden directamente en este hecho (Purcell, 2011) con lo que podría entenderse que es un efecto global y común en todo el entorno Mediterráneo.

El motivo del presente estudio es observar si existen diferencias apreciables entre áreas, ante un hecho universal, en esta tendencia generalizada al aumento de frecuencia y severidad de las floraciones de medusas, en cuyo caso las razones de la variabilidad entre zonas habría que investigarlas en las características estructurales de la costa. Se considera fundamental entender el comportamiento de estas floraciones de medusas, ya que afectan negativamente a actividades relacionadas con estos espacios litorales como la pesca, la acuicultura o el turismo (Richardson, Bakun, Hays y Gibbons, 2009).

Para analizar la incidencia y severidad se ha utilizado una aplicación de registro de medusas, InfoMedusa, abordando el problema mediante la colaboración de la población, la cual aporta, en esta y otras materias, conocimiento con uso científico que puede ser incorporado en las políticas públicas y, en este caso particular, puede ayudar en la implantación de medidas preventivas y/o paliativas del riesgo. Además, la contribución de la ciudadanía, puede ser muy beneficiosa para la comunidad, ya que siente formar parte del proceso (Danielsen, Burgess, Jensen y Pirhofer-Walzl, 2010). Los resultados que aportan este tipo de metodologías se equiparan a otro tipo de técnicas, más tradicionales, en las que intervienen profesionales del tema en cuestión, lo que argumenta a favor de esta técnica en estudios científicos (Cohn, 2008; Irwin, 1995; Theobald et al., 2015). Silvertown (2009) matiza la utilidad de esta técnica de investigación, indicando la necesidad de validar los datos que aporta el público participante y la necesidad de un buen diseño y estandarización para que los resultados no pierdan calidad.

En lo que se refiere a la calidad de la fuente utilizada en la investigación en relación a otras fuentes con similar aplicación, un análisis comparado de las prestaciones y limitaciones permite observar ventajas notables de InfoMedusa sobre otras opciones. Sus principales ventajas son la totalidad de observaciones por playa que aporta y la extensión temporal de los registros válidos (periodo 2015 a 2020). Como inconveniente puede mencionarse la detallada labor de interpretación de los datos que requiere, hecho que se relaciona con el carácter libre de las observaciones y comentarios que conforman la base de datos. Estas características exigen una labor extensa de traducción de los comentarios libres de la ciudadanía, para interpretarlos y obtener resultados útiles para el propósito del inventario.

Existen investigaciones, en el marco del litoral andaluz, que toman como referencia otras fuentes de información, cuya calidad y criterios de homogeneización es discutible (Rubio y Gutiérrez, 2020). Entre las otras aplicaciones y bases de datos de medusas disponibles en la Costa del Sol se encuentra la proporcionada por la Red de Información Ambiental de Andalucía (Rediam), que ofrece una disponibilidad temporal que abarca desde 1994 a 2017, para toda la costa andaluza. Esta base de datos podría, a priori, considerarse complementaria a InfoMedusa, ya que comienza con anterioridad a la serie 2015-2020 con la que se ha trabajado en este estudio. Un análisis de detalle de la fuente, sin embargo, descarta esta expectativa ya que Rediam, que se basa en la investigación de Prieto y Navarro (2013), no trabaja con datos en tiempo real proveniente de visitantes, lo que se traduce en un menor volumen de información. La aportación de tan sólo 12, 7 y 2 avistamientos en los años concurrentes de ambas bases de datos, esto es 2015, 2016 y 2017 respectivamente, se muestra como claramente insuficiente para la pretensión del presente estudio. Otra limitación de esta base de datos es que, además, carece de actualización, ya que está activa sólo hasta 2017.

Mayor similitud en prestaciones a InfoMedusa tiene la aplicación Medusapp, que aporta datos diarios y opera en el ámbito espacial requerido en este trabajo. Uno de los aspectos negativos de esta aplicación es el intervalo de años que comprende, que comienza en 2018, lo que la limita en este aspecto, además de que los registros u observaciones que muestra sean mucho menos abundantes. Si comparamos el año 2018, que constituye el que más avistamientos posee en ambas aplicaciones, la diferencia de datos es considerable, ya que Medusapp contiene 194 comentarios en comparación a los 98.004 de InfoMedusa, en ambos casos para el conjunto del tramo occidental de la Costa del Sol. Otras aplicaciones similares como MedJelly, Grumering u Oboradar operan fuera del ámbito de análisis, por lo que se descarta en un primer momento como fuentes de trabajo.

El análisis comparado de las prestaciones ofrecidas por la base de datos utilizada respecto a las otras fuentes mencionadas muestra con claridad que, a pesar de sus inconvenientes, las posibilidades que ofrecen los datos de InfoMedusa para el análisis de detalle de la frecuencia de avistamientos en la costa es incuestionablemente de mejor calidad. En este contexto, el inventario resultante de la presente investigación constituye una aportación especialmente valiosa, dada la inexistencia de una fuente de similar calidad y características en la zona de estudio. 
Tanto InfoMedusa como Medusapp, registran los datos a nivel de playa. El desarrollo del trabajo ha mostrado que el uso de la playa como unidad de trabajo básica para la representación y cálculo estadístico de la peligrosidad presenta ventajas e inconvenientes. El principal inconveniente es la extensión variable de la misma, hecho que distorsiona la interpretación de la alta o baja frecuencia de avistamientos, dado que no se parte de un espacio potencial de frecuentación de usuarios similar. La base de datos de Rediam, por el contrario, al obtener los datos mediante recopilación de información y el procesado de imágenes de satélite, carece de este tipo de problemática. Sin embargo, como ventaja fundamental del uso de la playa como unidad de trabajo, puede señalarse que constituye un marco para la evaluación y cartografía de la susceptibilidad, coherente con la unidad fisiográfica, geomorfológica y funcional litoral básica, y facilita, por ello, la interpretación de las relaciones entre el patrón de comportamiento espacial de las medusas con las causas precisas que lo puedan estar generando.

En lo que se refiere a la periodicidad de la toma de datos y la duración del periodo disponible, la fuente de datos explotada e inventariada ofrece una secuencia más sistemática que Medusapp y Rediam, con un ritmo menos frecuente y un periodo de datos menor, en el caso de Medusapp y poco actualizado con respecto a Rediam.

Por último, con respecto al formato de información ofrecida por estas tres fuentes, la más operativa es, sin lugar a dudas, Rediam, que ofrece datos en formato Shape (.shp) de fácil manejo y tratamiento mediante Sistemas de Información Geográfica (SIG). Medusapp, por su parte, requiere la captura de datos procedente de la aplicación y su tratamiento para poder importarlos al SIG, tarea que se realizó para verificar su utilidad en el estudio y cuyo uso se descartó por la insuficiente suma de registros anteriormente comentada. Por último, la base de datos de InfoMedusa, si bien es la más amplia con diferencia, también es la más exigente en dedicación y necesidades de tratamiento de los datos brutos (comentarios cualitativos en formato libre).

Por consiguiente, aunque la escala de trabajo sea similar en estos tres casos analizados, tanto el intervalo temporal como la disponibilidad y calidad de los datos, descarta a Rediam y Medusapp como fuente sistemáticas para comprender el comportamiento espacial de las medusas. A partir de la observación comparada de las potencialidades y limitaciones de la fuente de datos, puede afirmarse que el inventario de datos obtenido a partir de su explotación constituye, por sus características, una aportación valiosa y excepcional en el contexto de trabajo, fiable para generar indicadores de distribución espacial del fenómeno.

Respecto a los indicadores calculados para evaluar la propensión de las distintas playas a recibir medusas, como se ha comentado, se ha constatado en los mismos una limitación relativa a la diferencia de tamaño de la unidad espacial de observación (la playa) y la posible diferencia asociada a su frecuentación por usuarios. Este hecho puede proporcionar una interpretación confusa de la alta o baja presencia de días con medusas, ya que el dato puede estar motivado por una alta o baja frecuentación de usuarios en la playa. Para aquilatar este problema, se ha propuesto el indicador Número de días con medusas ponderado por la superficie de la playa y Número de días sin medusas ponderado por la superficie de la playa. Mediante la ponderación por la superficie se ha intentado suavizar el hecho probable de que los valores altos de días con medusas de una playa estén motivados por la alta frecuentación de usuarios en la misma. Se ha considerado una relación directa entre la extensión de la playa y la frecuentación de usuarios. Este factor de ponderación se ha ajustado con un coeficiente de minoración (superficie de la playa* 0,5 ) en los casos en los que la playa esté muy alejada de los circuitos de acceso urbano. Se intenta discriminar, de esta forma, las playas de grandes dimensiones urbanas (alto potencial de frecuentación tanto por el espacio disponible como por la cercanía a la ciudad como punto emisor de usuarios), respecto a las grandes playas alejadas de la ciudad y poco frecuentadas. En cualquier caso, en avances futuros de la investigación, se están calculando indicadores empíricos de frecuentación de las playas para afinar la representación del dato estadístico. Otros estudios han intentado resolver el problema de la homogeneización de datos planteado a través de distintas soluciones. En este sentido, Rubio y Gutiérrez (2020) elaboran una cartografía de los avistamientos basada en una cuadrícula de $5 \times 5 \mathrm{~km}$ sobre la que representan la cuantificación de las medusas. Este procedimiento puede ser apropiado para la escala de su investigación, ya que la unidad espacial de cálculo y representación es el municipio, pero no sería útil para el trabajo a nivel de playa. En otro estudio en la costa catalana, Benedetti-Cecchi et al. (2015) estudian los brotes de medusas por año, es decir, se analiza el patrón temporal, no el espacial, lo que hace innecesario calibrar los datos por áreas.

Los resultados estadísticos y cartográficos obtenidos permiten deducir que la distribución espacial de la llegada de medusas a la costa no presenta un patrón aleatorio en las playas del tramo estudiado. Al analizar los resultados en su conjunto, se aprecia una clara tendencia al aumento de los avistamientos de medusas conforme se avanza hacia las playas más occidentales, siendo éstas por lo tanto las que presentan una mayor peligrosidad de afección por medusas. En el lado opuesto, las playas más orientales disfrutan de más registros de ausencia de medusas, siendo, por consiguiente, menos proclives a su presencia. 
Algunos autores han avanzado en la búsqueda de un patrón espacial de la distribución de los enjambres. A una escala regional, de mucho menos detalle, Canepa et al. (2014) atribuyen los avistamientos costeros en el mar Adriático a la dirección y velocidad del viento y al efecto de las mareas, ya que se trata de aguas costeras poco profundas, lo que favorece grandes acumulaciones de medusas. Estos mismos autores, en un estudio del litoral de Cataluña, concluyen que, si bien las observaciones de presencia de medusas están extendidas a lo largo de toda la costa, tienen a concentrase con mayor frecuencia en las playas cercanas a los cañones submarinos, que actúan como "superautopistas" desde las aguas más profundas. A escala de la Costa del Sol, Gutiérrez-Estrada et al. (2021) identifican, al igual que Canepa et al. (2014), la velocidad y la dirección del viento como factores clave que determinan el momento y la intensidad de la llegada de las medusas a las playas. En el mismo entorno geográfico, Rubio y Gutiérrez (2020), que analizan la totalidad de la costa andaluza, relacionan una posible causa de los avistamientos con accidentes geográficos como bahías, ensenadas y costas altas con presencia de calas. Estos autores identifican la localización hacia levante, en el tramo que se extiende desde el municipio malagueño de Torrox hasta Motril en Granada como el más proclive a recibir medusas. En nuestro estudio, sin embargo, no se percibe esta tendencia, sino la contraria, en la que la peligrosidad de las playas aumenta hacia el oeste. Posiblemente motivado por el mayor nivel de detalle de nuestro estudio, puede observarse una explicación coherente a estos hechos, en principio, contradictorios. Debido a la propia incurvación del litoral mediterráneo andaluz, las playas que muestran una mayor propensión en nuestro análisis se posicionan en las franjas de costa orientadas al flujo de levante, desde dónde los estudios más generales afirman que provienen los enjambres, que se trasladan hacia la orilla desde el mar de Alborán (Bellido et al., 2020).

A nivel de detalle, un análisis preliminar de la distribución espacial observada en nuestro estudio, permite asociar la distribución la mayor frecuencia de avistamientos de medusas a una serie de factores que pueden estar actuando como condicionantes. Más que la localización hacia el sector oriental de la costa, se han identificado como posibles causas de la mayor peligrosidad de algunas playas aspectos como su orientación sureste, el mayor ángulo de apertura de la playa y la ausencia de una protección lateral de la playa respecto al flujo de levante. Según se ha constatado, las playas de ángulo más abierto y orientadas hacia el este y sudeste, presentan una mayor frecuencia de enjambres. Este hecho pone de manifiesto que, cuando el análisis se realiza a nivel de detalle, la orientación de la embocadura de la playa hacia la zona de procedencia predominante de los enjambres, puede determinar la susceptibilidad, en mayor medida, que la propia localización de la playa. De las playas muestreadas en este estudio, El Cristo, más cerrada y con una orientación suroeste, que además se encuentra resguardada del flujo de levante por una barra de protección lateral en su extremo este, presenta un menor grado de peligrosidad que las de su entorno.

La hipótesis que explica la distribución de la peligrosidad observada, como resultante de la orientación del tramo de costa en el que se ubica la playa y su apertura al flujo de levante, se comprueba, igualmente, al analizar el sector oriental del tramo analizado, que presenta playas menos proclives a la aparición de medusas. La protección frente al viento del este que le otorga la propia bahía de Málaga, abierta hacia el poniente, puede explicar esta menor propensión en las playas más orientales. Los valores más bajos de frecuencia de medusas en este sector costero también podrían relacionarse con la proximidad de las playas a fuentes de aporte de agua dulce, debido al río Guadalhorce. Autores como Bellido et al. (2020), citan la posible incidencia de este variable en la distribución espacial de las floraciones de medusas en el litoral y su llegada hasta las zonas de playa desde mar adentro.

\section{Conclusiones}

La base de datos ofrecida por InfoMedusa proporciona una información esencial en lo que se refiere al conocimiento y gestión del problema de la afección por medusas. Su uso con propósitos científicos, no obstante, requiere de un tratamiento detallado y profuso de la información bruta para, después de un proceso de depuración y filtrado, obtener datos fiables. Sus potencialidades como fuente para el análisis del patrón espacial de afección de medusas en el litoral se muestran superiores a las ofrecidas por otras bases de datos de propósito similar, que resultan muy insuficientes. En este contexto, el inventario de datos aportado en la investigación adquiere una especial relevancia, dado la inexistencia de inventarios de datos de similares prestaciones en el ámbito costero andaluz.

La variabilidad en los resultados de presencia o ausencia de medusas entre las distintas playas a lo largo del periodo analizado permite afirmar que existe un patrón de distribución de la peligrosidad no aleatorio. La pauta de distribución observada refleja una tendencia al aumento de la presencia de medusas conforme la playa se localiza en sectores más occidentales de la zona de estudio. Factores como la orientación abierta de las playas más proclives hacia las corrientes provenientes de levante, por la orientación general de la costa, puede relacionarse con el incremento de la susceptibilidad en las playas en el sector occidental de la zona de análisis. La orientación a sotavento respecto a los flujos de levante de las playas 
más orientales puede explicar, de igual modo, la menor frecuencia de medusas en estas playas. Este patrón espacial no aleatorio y la coherencia general, entre el modelo de distribución espacial de la aparición de enjambres y factores explicativos asociados a la morfología y funcionamiento del litoral, permiten observar, a pesar de sus limitaciones, la potencialidad como fuente del inventario que se ha elaborado, así como la validez de los indicadores de peligrosidad.

El comportamiento diferenciado de las playas objeto de estudio, que se ha constatado en este trabajo, anima a plantear futuras hipótesis, más complejas, en lo que se refiere a otros posibles factores subyacentes al patrón de susceptibilidad observado, que puedan estar causando las diferencias de afección, para avanzar hacia la generación de un modelo predictivo. La explotación de los datos sobre presencia de medusas y la metodología de análisis aplicada en la investigación, han permitido concluir aportaciones de carácter inédito y de interés para el análisis de la afección de medusas en el litoral. Los resultados ofrecen una base de partida sólida para extender el área de estudio e indagar con mayor profundidad en la identificación de factores condicionantes, al objeto de realizar cartografías predictivas de la susceptibilidad en otras zonas costeras.

\section{Agradecimientos}

Los autores agradecemos a J. Bellido (Aula del Mar. Málaga) el acceso a los datos que constituyen la fuente en que se fundamenta el trabajo (InfoMedusa).

\section{Referencias}

Aforo Costa del Sol (s.f.). Torremolinos-Planifica tu visita a la playa. Recuperado de https://aforocostadelsol. es/torremolinos/

Aula del Mar de Málaga (2021). InfoMedusa. Recuperado de https://infomedusa.es

Aula del Mar (2021). Medusas en la provincia de Málaga. Recuperado de https://infomedusa.es/picadurade-medusa

Ayuntamiento de Casares (s.f.). Casares. Playas. Recuperado de http://www.casares.es/turismo/playas-2/

Bellido, J., Baez, J., Souviron-Priego, L., Ferri-Yañez, F., Salas, C., López, J. A., \& Real, R. (2020). Atmospheric indices allow anticipating the incidence of jellyfish coastal swarms. Mediterranean Marine Science, 21(2), 289-297. http://dx.doi.org/10.12681/mms.20983

Bellido, J., Souviron, L., Báez, J. C., Ferri-Yañez, F., \& Salas, C. (2018). Seguimiento de un enjambre de Pelagia Noctiluca en la costa de la provincia de Málaga. I Foro del Mar de Alborán. Encuentro de mares, ciencias y culturas (pp. 99-102). Fuengirola. Recuperado de http://www.uicn.es/web/pdf/ XIV_foro/09\%20AuladelMar_Infomedusa2.pdf

Benedetti-Cecchi, L., Canepa, A., Fuentes, V., Tamburello, L., Purcell, J. E., Piraino, S., R., ... \& Halpin, P. (2015). Deterministic Factors Overwhelm Stochastic Environmental Fluctuations as Drivers of Jellyfish Outbreaks. PLOS ONE, 10(10), e0141060. https://doi.org/10.1371/journal.pone.0141060

Brotz, L., Cheung, W. W. L., Kleisner, K., Pakhomov, E., \& Pauly, D. (2012). Increasing jellyfish populations: trends in Large Marine Ecosystems. Hydrobiologia, 690(1), 3-20. https://doi.org/10.1007/s10750-0121039-7

Calvo, F. (2001). Sociedades y territorios en riesgo. Barcelona: Ediciones del Serbal.

Canepa, A., Fuentes, V., Sabatés, Piraino, S., \& Boero, F. (2014). Pelagia noctiluca in the Mediterranean Sea. En Pitt K., Lucas C. (Eds), Jellyfish Blooms (pp. 237-266). Netherlands, Dordrecht: Springer. http://dx.doi.org/10.1007/978-94-007-7015-7_11

Cohn, J. P. (2008). Citizen Science: Can Volunteers Do Real Research? BioScience, 58(3), 192-197. https:// doi.org/10.1641/B580303

Condon, R. H., Duarte, C. M., Pitt, K. A., Robinson, K. L., Lucas, C. H., Sutherland, K. R., ... \& Graham, W. M. (2013). Recurrent jellyfish blooms are a consequence of global oscillations. Proceedings of the National Academy of Sciences of the United States of America, 110(3), 1000-1005. https://doi. org/10.1073/pnas.1210920110

Consejería de Agricultura, Ganadería, Pesca y Desarrollo Sostenible (s.f.). Dunas de Artola o Cabopino III. Recuperado de https://www.juntadeandalucia.es/medioambiente/portal/web/ventanadelvisitante/ detalle-buscador-mapa/-/asset_publisher/Jlbxh2qB3NwR/content/dunas-de-artola-o-cabopino-2

Costalsur (s.f.). Playa El Cable en Marbella. Recuperado de https://marbella.costasur.com/sites/el-cable/ es/index.html 
Cutter, S. (1994). Environmental Risk and Hazards. Englewood Cliffs: Prentice-Hall.

Danielsen, F., Burgess, N. D., Jensen, P. M., \& Pirhofer-Walzl, K. (2010). Environmental monitoring: the scale and speed of implementation varies according to the degree of peoples involvement. Journal of Applied Ecology, 47(6), 1166-1168. https://doi.org/10.1111/j.1365-2664.2010.01874.x

Diario Sur (s.f.). Playa Guadalhorce. Infoplayas Recuperado de https://www.diariosur.es/planes/playas/ malaga/guadalhorce-0002131.html

Diario Sur (s.f.). Playa La Rada. Infoplayas. Recuperado de https://www.diariosur.es/planes/playas/malaga/ la-rada-0000028.html

Diario Sur (s.f.). Playa Los Álamos. Infoplayas. Recuperado de https://www.diariosur.es/planes/playas/ malaga/los-alamos-0002204.html

Diputación de Málaga. (s.f.). Las Gaviotas. Recuperado de https://www.malaga.es/en/turismo/naturaleza/ lis_cd-4376/las-gaviotas

Dong, Z. (2019). Blooms of the Moon Jellyfish Aurelia: Causes, Consequences and Controls. In: Sheppard S. En World Seas: an Environmental Evaluation (Second Edition) Volume III: Ecological Issues and Environmental Impacts. Academic Press, Amsterdam (pp. 163-171). http://dx.doi.org/10.1016/B978-0$\underline{12-805052-1.00008-5}$

Duarte, C. M., Pitt, K. A., Lucas, C. H., Purcell, J. E., Uye, S., Robinson, K., ... \& Condon, R. H. (2013). Is global ocean sprawl a cause of jellyfish blooms? Frontiers in Ecology and the Environment, 11(2), 91-97. https://doi.org/10.1890/110246

Enríquez, A. R., \& Bujosa, A. (2020). Measuring the economic impact of climate-induced environmental changes on sun-and-beach tourism. Climatic Change, 160(2), 203-217. https://doi.org/10.1007/ $\underline{\text { s10584-020-02682-w }}$

Ghermandi, A., Galil, B., Gowdy, J., \& Nunes, P. A. L. D. (2015). Jellyfish outbreak impacts on recreation in the Mediterranean Sea: welfare estimates from a socioeconomic pilot survey in Israel. Ecosystem Services, 11, 140-147. https://doi.org/10.1016/j.ecoser.2014.12.004

Goy, J., Morand, P., \& Etienne, M. (1988). Long-term fluctuations of Pelagia noctiluca (Cnidaria, Scyphomedusa) in the western Mediterranean Sea. Prediction by climatic variables. Deep Sea Research, 36(2), 269-279. https://doi.org/10.1016/0198-0149(89)90138-6

Gutiérrez-Estrada, J. C., Pulido-Calvo, I., Perregrín, A., García-Gávez, A., Báez, J. C., Bellido, J. J., ... \& López, J. A. (2021). Integrating local environmental data and information from non-driven citizen science to estimate jellyfish abundance in Costa del Sol (southern Spain). Estuarine, Coastal and Shelf Science, 249, 107112. https://doi.org/10.1016/j.ecss.2020.107112

Inspain. (s.f.). Playa de Sabinillas. Recuperado de https://www.inspain.org/es/malaga/manilva/playas/ sabinillas/

Irwin, A. (1995). Citizen Science: A Study of People, Expertise, and Sustainable Development. Routledge.

Kogovsek, T., Bogunovic, B., \& Malej, A. (2010). Recurrence of bloom-forming scyphomedusae: wavelet analysis of a 200-year time series. Hydrobiologia, 645, 81-96. https://doi.org/10.1007/s10750-010$\underline{0217-8}$

Mills, C. (2001). Jellyfish blooms: Are populations increasing globally in response to changing ocean conditions? Hydrobiologia, 451, 55-68. https://doi.org/10.1023/A:1011888006302

MITECO (2021). Guía de Playas. Madrid: Ministerio para la Transición Ecológica y el Reto Demográfico. Retrieved from https://www.miteco.gob.es/es

Narrogeographic (16/09/2011). Playa de Los Boliches, en Fuengirola. Recuperado de http://narrogeographic. blogspot.com/2011/09/playa-de-los-boliches-en-fuengirola.html

Nunes, P., Loureiro, M., Piñol, L., Sastre, S., Voltaire, L., \& Canepa, A. (2015). Analyzing Beach Recreationists' Preferences for the Reduction of Jellyfish Blooms: Economic Results from a StatedChoice Experiment in Catalonia, Spain. PLOS ONE, 10, e0126681. https://doi.org/10.1371/journal. pone. 0126681

Olcina, J. (2008). Cambios en la consideración territorial, conceptual y de método de los riesgos naturales. In X Coloquio Internacional de Geocrítica, Diez años de cambios en el mundo, en la Geografía y en las ciencias sociales, 1999-2008. Barcelona, 26-30 de mayo de 2008. Recuperado de http://www.ub.edu/ geocrit/-xcol/62.htm

Olmedo, J. M. (2019). Elaboración de un modelo multi-variable predictivo para el riesgo de proliferación de medusas en Málaga (Manuscrito inédito). Universidad de Málaga. Málaga. 
Perles, M., \& Cantarero, F. (2010). Problemas y retos en el análisis de los riesgos múltiples del territorio. Propuestas metodológicas para la elaboración de cartografías multi-peligros. Boletín de La Asociación de Geógrafos Españoles, 52, 245-271. Recuperado de https://bage.age-geografia.es/ojs/index.php/bage/ article/view/1171

Perles, M.J., \& Mérida, M. (2010). Patrón territorial y conformación del riesgo en espacios periurbanos. El caso de la periferia este de la ciudad de Málaga. Revista Scripta Nova, XIV(329). Recuperado de http://www.ub.es/geocrit/sn/sn-329.htm

Prieto, L., \& Navarro, G. (2013). Avistamientos de medusas en el litoral andaluz. Cádiz, España: Instituto de Ciencias Marinas de Andalucía, ICMAN (CSIC).

Purcell, J., Uye, S., \& Lo, W. (2007). Anthropogenic causes of jellyfish blooms and their direct consequences for humans: a review. Marine Ecology Progress Series, 350, 153-174. https://doi. org/10.3354/meps07093

Purcell, J. E. (2011). Jellyfish and Ctenophore Blooms Coincide with Human Proliferations and Environmental Perturbations. Annual Review of Marine Science, 4(1), 209-235. https://doi.org/10.1146/ annurev-marine-120709-142751

Richardson, A. J., Bakun, A., Hays, G. C., \& Gibbons, M. J. (2009). The jellyfish joyride: causes, consequences and management responses to a more gelatinous future. Trends in Ecology E Evolution, 24(6), 312-322. https://doi.org/10.1016/j.tree.2009.01.010

Rubio, A., \& Gutiérrez, O. (2020). Impacto de las medusas y otros organismos gelatinosos en el litoral andaluz. Implicaciones para el turismo de sol y playa. Estudios Geográficos, 81(288), e038. https://doi. org/10.3989/estgeogr.202053.033

Sabatés, A., Pagès, F., Atienza, D., Fuentes, V., Purcell, J., \& Gili, J.-M. (2010). Planktonic cnidarian distribution and feeding of Pelagia nociluca in the NW Mediterranean Sea. Hydrobiologia, 645, 153-165. https://doi.org/10.1007/s10750-010-0221-z

Silvertown, J. (2009). A new dawn for citizen science. Trends in Ecology E Evolution, 24(9), 467-471. https://doi.org/10.1016/j.tree.2009.03.017

Theobald, E. J., Ettinger, A. K., Burgess, H. K., DeBey, L. B., Schmidt, N. R., Froehlich, H. E., ... \& Parrish, J. K. (2015). Global change and local solutions: Tapping the unrealized potential of citizen science for biodiversity research. Biological Conservation, 181, 236-244. https://doi.org/10.1016/j. biocon.2014.10.021

Turismo y Planificación Costa del Sol S.L.U. (s.f.). Playa de Guadalmar. Costa del Sol Málaga. Recuperado de https://www.visitacostadelsol.com/malaga-costa-del-sol/playas/playa-de-guadalmar-p17211

Turismo y Planificación Costa del Sol S.L.U. (s.f.). Playa de El Cristo. Costa del Sol Málaga. Recuperado de https://www.visitacostadelsol.com/malaga-costa-del-sol/playas/playa-de-el-cristo-p20881

Veyret, Y., Beucher, S., \& Bonnard, Y. (2005). Risques naturels et territoires. Bulletin de l'Association de géographes français, 82(1), 63-74. https://doi.org/10.3406/bagf.2005.2440 